\title{
Capacitação para os Atendimentos do Conselho Tutelar de Vassouras/RJ
}

\author{
Arnaldo Risman \\ Universidade Severino Sombra, CELCSAH, Psicologia \\ Rismanerisman.psc.br \\ Gabriela Medeiros Vieira \\ Universidade Severino Sombra, CELCSAH, Psicologia \\ gabrielam_vieira@yahoo.com.br \\ Franciane Cesar Motta \\ Universidade Severino Sombra, CELCSAH, Psicologia \\ franciane.motta@yahoo.com.br \\ Geovana Rodrigues de Oliveira \\ Geovana.oliveirarodrigues@gmail.com \\ Lívia Azevedo de Souza \\ Universidade Severino Sombra, CELCSAH, Psicologia \\ Psico.livia@hotmail.com
}

Resumo: Os crimes sexuais envolvendo crianças e adolescentes são comuns na atualidade. Contudo, são muitas vezes subnotificados, ou tratados inadequadamente pela ausência de habilidades dos agentes do Conselho tutelar em lidar com este tipol de comportamento. O objetivo deste artigo foi descrever um curso de capacitação de um grupo de funcionários do Conselho Tutelar da cidade de Vassouras-RJ, quanto aos atendimentos e abordagens feitas com crianças elou adolescentes, que sofreram algum dano físico ou psicológico no campo da pedofilia. Método: A partir de aula expositiva e construção de material didático, elaborado a partir de artigos dos bancos de dados Scielo, Medline e Google, estagiários e professores fizeram treinamento com 10 membros do conselho tutelar no periodo de 22 a 24 de março de 2010. Chega-se à conclusão que desenvolver habilidades do entrevistador, na identificação e condução psicológica e jurídica dos casos, melhora não apenas a qualidade do atendimento, assim como fornece informações precisas aos órgãos competentes.

Palavras-chaves: Capacitação. Pedofilia. Psicologia 


\title{
Training Course for Minors Tutelar Council Agents in Vassouras, Rio de Janeiro
}

\begin{abstract}
Nowadays, sexual crimes involving children and adolescents are common. However, they are often underreported and inadequately dealt with due to Minors 'Tutelar Council's agents lack of skills when dealing with this kind of fact. The aim of this paper is to describe a training course for a group of employees from Tutelar Council in Vassouras and enable them to take care of and deal with children and adolescents who have suffered physical or psychological injury concerning pedophilia. Method: from scientific literature, it was prepared expositive teaching material, drawn from articles found in Scielo, Medline and Google data bases. Staff trained and professors uttered a training to 10 membership of Tutelar Council from March the 22nd to the 24th, 2010. Considerations: developing skills of interviewing and identifying cases as well as the psychological and legal conduction of cases not only improve the quality of guidance but also prove accurate information to the competent agents who deal with sexually violated victims.
\end{abstract}

Keywords: Psychology. Guidance. Pedophilia.

\section{Introdução}

As práticas sexuais envolvendo crianças e adolescentes têm ocorrido ao longo dos tempos, em várias culturas e em todas as classes sociais. Contudo, a forma como o tema vem sendo abordado e tratado é diferente, pois também esteve (sempre) sujeito às normas sociais vigentes. Por exemplo, na Grécia Antiga, há registros de pinturas de homens fazendo algum tipo de ato sexual com crianças e adolescentes, de forma consentida pelos pais e sendo uma honra aos mesmos, pois os mestres tornavam-se mentores das crianças. No Renascimento e durante a Idade Média, casamentos com crianças eram bem comuns pelo fato de as mesmas terem um jeito adorável e inocente, por serem mais bonitas e delicadas supostamente reproduzindo uma prole privilegiada (Tanahill, 1986). Enfim, fatores sócioculturais sempre estiveram atrelados e justificam de forma particular as práticas sexuais com crianças.

Há apenas um século atrás (por volta de 1860) foi publicado o primeiro trabalho científico sobre maus-tratos contra crianças e adolescentes e esse tema passou a ser um problema de saúde pública (Aded, Dalcin, Moraes \& Cavalcanti, 2006). Foi Ambroise Tardieu, um médico-legista francês, em 1860, o primeiro cientista que descreveu as formas de violência cometidas a crianças, a partir de evidências físicas de abuso. E, sob a influência de Tardieu, Sigmund Freud descreveu a etiologia da histeria em 1896 a partir de práticas de abusos sexuais da infância.

Entretanto, após críticas severas da sociedade, elaborou a teoria sobre o Complexo de Édipo, fundamentando-a em fantasias sobre relações parentais (Aded, Dalcin, Moraes \& Cavalcanti, 2006). 
Atualmente, as organizações internacionais de saúde, incluindo o Brasil, tratam da violência sexual como um tema de saúde pública. Em 1990, foi aprovada a Lei Federal de 8.060 de 13 de julho de 1990, com o Estatuto da Infância e Adolescência (ECA), formalizando não o crime "pedofilia", mas a violação dos direitos e da segurança da criança, tornando a prática sexual com crianças e adolescentes uma conduta criminosa.

Embora na Constituição brasileira não exista um tipo penal para pedofilia, esse se enquadra juridicamente em estupro (art.213 do Código Penal) e atentado ao pudor (art. 214 do Código Penal). Ambos os casos com pena de seis a dez anos de reclusão, sendo considerados crimes hediondos. No Brasil, qualquer ato sexual cometido com crianças menores de 14 anos é considerado pedofilia. Abaixo realizamos um quadro para facilitar os conceitos ligados a sexualidade:

Em 2003, o crime pedofilia configura-se em: “Artigo 240: Produzir ou dirigir representação teatral, televisiva, cinematográfica, atividade fotográfica ou de qualquer outro meio visual, utilizando-se criança ou adolescente em cena pornográfica, de sexo explicito ou vexatória. Incorre na mesma pena quem, nas condições referidas neste artigo, contracena com criança ou adolescente." E Artigo 241: “Apresentar, produzir, vender, fornecer ou publicar qualquer meio de comunicação, inclusive rede municipal de computadores ou Internet, fotografias ou imagens com pornografia ou cena de sexo explícita envolvendo criança ou adolescente", as penas variam de 2 a 8 anos e implicam em cobrança de multa (BRASIL, 1990).

Essas possibilidades de enquadramento da pedofilia em ação criminal proporcionaram a partir de 2007 o Conselho da Criança e do Adolescente junto com a coordenadoria de Direitos Humanos, estabelecerem uma ampla campanha contra a Pedofilia, por denúncias anônimas através de telefonemas, cujo número pode ser utilizado em qualquer lugar do Brasil, para denunciar qualquer tipo de abuso.

Para justificar o combate à violência contra crianças e adolescentes, poderíamos recorrer aos dados epidemiológicos. Contudo, o próprio Ministério da Saúde, enquanto órgão federal, reconhece que menos de $10 \%$ dos casos de violência sexual (a adultos e crianças) são notificados nas delegacias (Ministério da Saúde, 1999, apud, Souza e Adesse, 2005). Por questões relacionadas, em parte, de descrédito da população nas instâncias judiciárias e de segurança pública, por medo e vergonha das vítimas em denunciar ofensas sexuais, por medo de perder o emprego, das atitudes de toda a sociedade - atitudes estas que naturalizam a subalternidade das vítimas e uso da violência na resolução de conflitos (Articulação de Mulheres Brasileiras, 2000). A subnotificação da violência sexual é motivada também pela dificuldade da sociedade em lidar com a questão nos diferentes setores: judiciário, de segurança e de saúde.

Segundo dados extraidos de pesquisas feitas pela Secretaria Especial de Políticas para Mulheres (Souza e Adesse, 2005), o diagnóstico preliminar sobre violência sexual no estado do Rio de Janeiro realizado pela extinta Subsecretaria Estadual de Segurança da Mulher, registraram que das 1.383 vítimas de estupro estudadas em 2001, 51,6\% eram adultas e $48 \%$ eram crianças e adolescentes; e das 1.770 vítimas de atentado violento ao pudor, $24 \%$ eram adultas e $74 \%$ eram crianças e adolescentes; $76 \%$ eram do sexo feminino, enquanto que $23 \%$ eram do sexo masculino. Entre os agressores dos estupros, 
$52,2 \%$ eram conhecidos, sendo que 13,5\% tinham relação amorosa e/ou conjugal com a vítima e $37 \%$ eram desconhecidos. Entre os agressores de atentado violento ao pudor, $70,4 \%$ eram conhecidos, sendo que 5,5\% tinham relação amorosa e/ou conjugal com a vítima e 19\% eram desconhecidos. Setenta e dois por cento das vítimas de estupro no estado do Rio de Janeiro apresentaram intervalo de 4,8 horas entre o fato ocorrido e a comunicação, enquanto que o mesmo intervalo foi encontrado entre $69,8 \%$ das vítimas de atentado violento ao pudor (Asplan, 2002). Contudo, o acesso a bancos de dados que contenham estes recentemente é difícil, assim como costumam ser subestimados pelas subnotificações. Da mesma forma acontece no Município de Vassouras, Rio de Janeiro.

Diante do número de casos muitas vezes subnotificados de violência sexual contra crianças e adolescentes e da importância deste tema para a sociedade, foi criado o Projeto de Pesquisa "Pedofilia: em defesa de um corpo em desenvolvimento". Uma parceria com o Conselho Tutelar (CT), do Juiz local com a Universidade Severino Sombra (USS), vinculado com CEPCOS (Centro de Estudo e Pesquisa do comportamento e Sexualidade de São Paulo), com o apoio da Funadesp, do Fórum da Comarca de Vassouras / RJ, Secretarias de Saúde e Educação do município.

A missão do projeto vai desde fornecer as informações sobre o tema à população, até atender as vítimas de abuso sexual e seus familiares. Visto que as questões que envolvem as crianças e os adolescentes estão ligadas a diversos órgãos governamentais, foi criada uma parceria com o Conselho Tutelar (CT), um dos principais órgãos nos quais ocorrem as denúncias (enquanto pedidos de socorro), e os primeiros "atendimentos" às vítimas de abuso, a seus cuidadores e familiares, e ao próprio abusador. Contudo, os conselheiros e atendentes frente à escassez de informações sobre o assunto, mostraramse pouco capacitados a oferecer um suporte no atendimento às vítimas e, muitas vezes, os casos acabavam não sendo notificados, ou a queixa era "retirada" pelos cuidadores das mesmas. Então, em parceria com o Conselho Tutelar, foi elaborado um projeto de capacitação dos membros desse órgão. $O$ foco principal da capacitação foi auxiliá-los na estruturação de uma conduta ética e eficaz na abordagem dos casos suspeitos de pedofilia, através da informação sobre os atributos que o entrevistador deve possuir ao atender os casos suspeitos, da avaliação da veracidade do relato apresentado e a importância das informações conseguintes, fornecidas aos familiares dos casos suspeitos.

O objetivo do atual estudo é descrever o curso de capacitação oferecido a 10 membros do Conselho Tutelar do Município de Vassouras, Rio de Janeiro.

O curso pretendeu desenvolver habilidades sobre o conhecimento do comportamento pedofílico, desenvolver habilidades capacitando os envolvidos a diferenciar conceitualmente as agressões contra criança/adolescente e os prejuízos causados às vítimas de abuso sexual, assim como instruí-los sobre as questões jurídicas que enlaçam o tema. 


\section{Método}

O curso foi oferecido no período 22 a 24 de março de 2010, perfazendo uma carga horária de quinze horas, com a frequência de um total de 10 pessoas, compostos por vigias, assistentes sociais, uma acadêmica do curso de enfermagem e conselheiros. $\mathrm{O}$ curso foi realizado no Campus da Universidade Severino Sombra, em Vassouras, através de aulas expositivas e com o recurso de imagem (data-show) e material didático elaborado através das leituras e percepções de artigos selecionados das bases de dados Scielo, Google e Medline. Foi ministrado por estagiários devidamente treinados e sob supervisão e acompanhamento do Professor Arnaldo Risman, da Psicóloga Ana Patrícia Berion Ferreira e da Professora e Psicóloga Gabriela Medeiros Vieira.

\section{Atividades Realizadas}

O primeiro dia de capacitação do grupo consistiu na coleta de informações sobre o atendimento, privacidade, sobre espaço físico, assim como sigilo. Após a coleta dos dados, a equipe forneceu orientação sobre os procedimentos a serem tomados pelos entrevistadores, assim como a importância de um local adequado para as entrevistas. Também foi apresentado um breve histórico e conceito sobre a pedofilia, abuso sexual, e as formas com que as quais a parafilia se apresentam.

No segundo dia, foram abordadas as consequências do abuso sexual às partes envolvidas, como as alterações emocionais, cognitivas, comportamentais, distúrbios corporais, entre outros. Foram reforçados os pressupostos sobre as caraterísticas que o entrevistador deve apresentar como: confiança, honestidade, responsabilidade, sinceridades entre outros.

No terceiro e último dia dos encontros, um dos temas abordados foi a necessidade das habilidades do saber teórico e prático de cada entrevistador, a partir dos valores e normas de condutas sociais. Durante as entrevistas, não se deve transparecer, através do comportamento, nas expressões faciais, por exemplo, algum tipo de repressão ou mal estar.. O entrevistado, quando vai ao Conselho, tem o objetivo de buscar uma ajuda, um apoio, e os conselheiros tem que se mostrar dispostos ao acolhimento e à escuta.. Outra habilidade que o entrevistador deve apresentar é o conhecimento da rede de apoio que a cidade oferece, nesse caso, a cidade de Vassouras, para que possa melhor direcionar o entrevistado a partir de seu relato, tanto para fornecer uma estrutura de apoio psicológico, e jurídico.

A seguir, há a descrição das diretrizes consideradas à capacitação realizada:

\section{Material Didático}

\section{Habilidades gerais do entrevistador ao atendimento às vítimas de abuso sexual}

$\mathrm{O}$ entrevistador para oferecer acolhimento devido às vítimas de violência sexual deve ser devidamente treinado e apresentar as seguintes características:

Postura ética dos entrevistadores associado ao conhecimento prévio da dinâmica desta forma de violência; 
Humildade durante o atendimento e abertura para a constante aquisição do conhecimento;

Empatia - não mostrar-se apático ao trabalho, mostrar-se disposto a efetuá-lo de forma coerente;

Fazer perguntas (perguntas abertas) - com estas, o entrevistador não dá nenhuma possibilidade de opção de resposta ao entrevistado, o mesmo percebe a necessidade de falar sobre o fato, com suas palavras;

Operacionalizar informações - fazer com que os dados colhidos estejam ligados , não perder o elo das informações;

Levar a descrever sentimentos - ao ouvir algum tipo de sentimento pelo entrevistado, peça-o para descrevê-lo, a fim de mostrar o que o entrevistado pensa de cada um;

"Sumarizar ou resumir as informações - ao tratar de algum tipo de abuso sexual, o entrevistado por si sente um "bloqueio" ao falar de si e do fato ocorrido, muitos podem fazer rodeios para concluir o que deseja relatar, por isso a importância do resumo das informações. Não colocar fatos que podem influenciar, positivamente ou negativamente, sua entrevista;

Conduzir a entrevista - o entrevistador tem que ter um objetivo, um foco para não se perder na entrevista;

Manter sequência - seguir um roteiro;

Não prometer segredo - a criança ou adolescente pode pensar que irá sofrer novamente algum tipo de abuso, ou a repetição de algo que já aconteceu;

Ter valor ético;

Estar isento de conceitos e pré-conceitos - pode contaminar a entrevista caso tais valores forem empregados;

Saber ouvir para saber encaminhar - saber ouvir para melhor indicar o entrevistado a um atendimento direcionado;

Registrar os atendimentos - todo e qualquer procedimento deve ser registrado e catalogado, para evitar problemas jurídicos e para que tais registros possam ser utilizados como pesquisa futuramente;

Ter responsabilidade;

Conhecer os fatores de apoio - antes de direcioná-los, é de suma importância conhecer os fatores de apoio de sua cidade ou região, como exemplo: Ministério Público.

\section{Habilidades Específicas do Entrevistador}

O entrevistador deve possuir uma postura ética e uma visão ampla de conhecimento de onde está atuando como um sujeito de grande responsabilidade. Dessa forma, existem alguns pontos importantes que o entrevistador precisa construir em sua formação, são eles: 
Discernir entre seus problemas pessoais e os da criança; ver ou conhecer, notar discriminar, separar e distingui-los dos seus.

- Ser sincero e honesto; relatar somente o que ouvir, sem omitir ou acrescentar alguma informação.

Aceitar e compreender a criança; ter um trabalho de acolhimento, conquistar a confiança da criança para que a mesma possa relatar o ocorrido.

Estar seguro de si; estar seguro em sua entrevista para afirmar sua segurança ao entrevistado, tanto no relato, quanto na entrevista.

Ter a capacidade de facilitar a expressão da criança (manter o diálogo); saber colocar palavras certas, de compreensão para cada criança, manter um diálogo de acordo com a idade e a cultura desta.

Existem características de comportamento apresentadas pelas vítimas de abuso sexual que podem facilitar a sua identificação pelos entrevistadores:

\section{Comportamentos Característicos de Vítimas de Abuso Sexual (Manual Diagnóstico e Estatístico de Doenças Psiquiátricas Revisado, DSM IV-TR, 2000):}

Em geral, as vítimas podem apresentar um ou mais dos sinais e sintomas abaixo:

Ansiedade, pesadelos, insônias;

Dificuldade de caminhar e sentar;

Traumatismo físico ou lesões corporais, por uso de violência física;

Medo generalizado;

Agressividade, fugas frequentes de casa;

Mudanças extremas, súbitas e inexplicadas no comportamento, como oscilações no humor entre timidez e extroversão;

Tristeza, abatimento profundo ou depressão crônica. Fraco controle de impulsos e comportamento autodestrutivo ou suicida;

Ansiedade generalizada, comportamento tenso, sempre em estado de alerta, fadiga. Esgotamento físico;

Hipersexualidade - Brincadeiras de conotação sexual;

Mudança no comportamento, agressividade, falta de apetite, gagueira, hábitos compulsivos;

Vontade de querer ficar só, falta de aprendizagem;

Uso e abuso de substâncias como álcool, drogas lícitas e ilícitas;

Pontualidade exagerada, quando ainda frequenta a escola, demonstra pouco interesse ou mesmo resistência em voltar para casa após a aula; 
Não participação, ou pouca participação nas atividades escolares;

Dificuldade de concentração e aprendizagem, resultando em baixo rendimento escolar;

Alto índice de abandono escolar;

- Medo de adultos (principalmente se for do mesmo sexo do seu agressor)

- Surgimento de objetos pessoais, brinquedos, dinheiro e outros bens, que estão além das possibilidades financeiras da criança/adolescente e da família, pode ser indicador de favorecimento e/ou aliciamento;

Tendência ao isolamento social, com poucas relações com colegas e companheiros;

- Transtorno de déficit de atenção - hiperatividade;

- Transtornos alimentares, como bulimia e anorexia;

- Transtorno de estresse pós-traumático;

. Transtornos do sono;

Enurese (micção noturna);

A interação desde a primeira entrevista é essencial para a confiabilidade dos dados obtidos e, principalmente, para que a impressão da criança em relação aos entrevistadores e à instituição que estes representam seja de confiança (Silvares \& Gongora, 1998). Os entrevistadores devem proporcionar tempo suficiente para que as crianças e adolescentes exponham suas opiniões, anseios e idéias, sem se sentirem ameaçados. Os entrevistados também podem fazer perguntas e esclarecer suas dúvidas (Garbarino \& Scott, 1992).

\section{Veracidade do Relato}

Pontos importantes para ficar atento ao relato dos casos colhidos num atendimento.

A análise de validade da declaração (Statement Validity Analysis - SVA)

Possui 3 elementos: avaliação psicológica; análise de sua declaração; comprovação da validade.

Avaliação psicológica da vítima: tem como objetivo situar as declarações dentro de um contexto mais amplo, identificando fatores (criança-família - rede de atendimento) de risco e de proteção para o desenvolvimento da criança.

Avaliação de Conteúdo

1- características gerais (estrutura lógica $=$ coerência, produção desestruturada $=$ saltos de um assunto e quantidade de detalhes); 2- conteudos específicos ( adequação contextual , descrição de ações e reações mútuas entre vítima e agressor, reprodução de conversações e 
complicações inesperadas); 3- peculiaridades de conteúdo ( avalia a presença explícita de detalhes distintivos, emoções, associações e sentimentos) ; 4- conteúdo com motivação; 5- elementos específico da agressão.

\section{Considerações Finais}

Abordar o tema pedofilia é tarefa difícil. A ausência de notificação dos casos, associados aos sentimentos de culpa, vergonha e medo são reações comuns daqueles que sofrem violência, assim como seus familiares.

Tais comportamentos são uma reação frente às atitudes, no sentido amplo da palavra (atitude) como um conjunto de crenças, comportamentos e cognições (Bunchaft e Cavas, 2002), acerca de uma conduta que ao longo dos tempos vem recebendo a conotação social de delito, a violência sexual a crianças e adolescentes. Contudo, o tal comportamento é ainda frequente.

Segundo Santo e Dell'Aglio, 2008, existem dois tipos de violência sexual, a intrafamiliar e a extrafamiliar, tendo em vista o contexto em que ocorre. Em cada caso, existe uma rede social peculiar, com relações de poder envolvidas na conduta, e que devem ser levadas em conta. Em ambos os casos, medidas de ação primária como afastamento do agressor, intervenção familiar e intervenção clínica são necessárias. Sendo assim, um projeto que visa a capacitar um grupo de pessoas (conselheiros) que atenderão, primeiramente, as queixas sobre violência sexual, promove não apenas o entendimento e identificação do caso, mas o encaminhamento emergencial às instâncias cabíveis ao restabelecimento da segurança física e saúde mental da criança.

O conselheiro tutelar, também deve estar a par do sistema em que convive, das particularidades sociais e judiciais nas quais está inserido. Na cidade de Vassouras, por exemplo, historicamente e tradicionalmente um território de plantio do café, cujas relações sociais foram por anos constituídas sob o poder feudal, as relações de poder e subordinação ainda repercutem na história de determinadas famílias. Sendo assim, entender tais relações também facilita as ações de intervenção na conduta violenta.

Segundo estudos de casos realizados por Sanfelice e Antoni, 2010, o comportamento do pedófilo está diretamente relacionado à percepção do mesmo tema sobre sexualidade. Para Sanfelice e Antoni, 2010, os abusadores parecem organizar três tipos de teorias implícitas sobre o abuso: $1^{\circ}$ - abrange as crenças sobre as pessoas e o mundo em geral ( regras sociais que determinam que aquele que detém poder usufrui de seus bens); $2^{\circ}$ - diz respeito àquelas crenças intermediárias que categorizam os elementos em geral, como, por exemplo, os significados (comportamentos sexualizados e estimulantes) atribuidos às crianças; $3^{\circ}$ - teoria implícita ligada àquelas crenças que o abusador possui sobre objetos ou pessoas específicos, como padrões de percepções e pensamentos distorcidos são as causas pessoais para a agressão sexual e para outros domínios de comportamento. De qualquer forma parece que as crenças culturais aprendidas estão amplamente atreladas às justificativas de condutas de violência sexual sobre crianças.

Sabemos que mesmo com as repercussões que o tema pedofilia tem apresentado na sociedade, nada impedeainda que novos casos ocorreram nem, tampouco, determinem 
a punição de seus praticantes. Contudo, os cursos e a elaboração dos materiais didáticos criados pelo Projeto: "Pedofilia: em defesa de um corpo em desenvolvimento" têem o objetivo de instruir e multiplicar as informações sobre o tema e auxiliar os membros do CT na luta contra este crime. Sabemos que as veredas desta luta são sinuosas e cheias de descaminhos. Este foi o primeiro de muitos outros cursos, palestras e quaisquer outras formas de divulgações sobre a pedofilia. O projeto de pesquisa pretende fornecer informações precisas aos órgãos responsáveis e para a sociedade como um todo. 


\section{Referências}

Bauman, Zygmunt: Modernidade Líquida, $1^{a}$ Edição, 2001, Ed. Jorge Zahar.

Brasil. Lei 8.069, de 13 de julho de 1990. Estatuto da Criança e do Adolescente. Artigos 5, 165, 213, 214, 240 a 243. Disponível em: www.planalto.gov.br

Claudio de São Thiago Cavas e Guenia Schaft In: página 105. Atitude e sua mensuração,livro: "Sob Medida um guia sobre a elaboração de medidas do comportamento e suas aplicações- "- editora Vetor

Cordeiro, F.de A. Aprendendo a prevenir: orientações para o combate ao abuso sexual contra crianças e adolescentes. Brasília: Promotoria de Justiça de Defesa da Infância e da Juventude, 2006.

Costa, L. F, Penso, M. A., \& Almeida, T (2005). O grupo multidsciplinar um método de intervenção em situações de abuso sexual infantil. Psicologia USP, 16(4), 121-146.

Costa, L. F, Penso, M. A., \& Almeida, T (2007), Famílias com abuso sexual infantil: o dilema entre a mudança e a cristalização de influências transgerecionais Em C. M. O. Cerveny (Org) Família em movimento ( pp. 203-226). São Paulo: Casa do Pscólogo.

Croce, Delton, et alli. (1995) Manual de Medicina Legal, Saraiva, São Paulo, 1995.

Dell'Aglio, Débora Dalbosco, Estudos de Psicologia I Campinas I 25(4) I 595-606 I outubro - dezembro 2008 Compreendendo as mães de crianças vítimas de abuso sexual: ciclos de violência, Samara Silva dos SANTOS1.

DSM-IV -Tr- Manual diagnóstico e estatístico de transtornos mentais. Porto Alegre, Ed. Artes Médicas, 2000.

Garbarino, J, \& Scott, F. M. (1992). What children can tell us: eliciting, interpreting and evaluating critical information from children? São Francisco: Jossey-Bass.

Haas, A. O abuso sexual cometido contra a criança e o adolescente: uma visão intrafamiliar. Disponível em www.abmp.org.br/textos, Acesso 08. março. 2010.

Habigzang, L. F., Caminha, R. M. (2004). Abuso sexual contra crianças e adolescente: conceituação e intervenção clínica. São Paulo: Casa do Psicólogo.

Hooper, C-A. (1994) Madres sobreviventes al abuso sexual de sus niños. Buenos Aires: nueva Visión.

Massia Sanfelice, Mirela; Antoni, Clarissa De. (2010) A Percepção do Abusador Sexual sobre a (Sua) Sexualidade Interamerican Journal of Psychology, vol. 44, núm. 1, 2010, pp. 131-139 Sociedad Interamericana de Psicología / Interamerican Society of Psychology Austin, Puerto Rico.

Ministério Público. A Violência contra crianças \& adolescentes. Volta Redonda, 2009.

Naura Liane de Oliveira Aded, Bruno Luís Galluzzi da Silva Dalcin, Talvane Marins de Moraes, Maria Tavares Cavalcanti. Abuso sexual em crianças e adolescentes: revisão de 100 anos de literatura

Saywitz, K. J., Mannarino, A. P., Berliner, 1. \& Cohen, J. A. (2000). Treatment for sexually abused children and adolescents. American Psychologist, 55 (9), 1040-1049. 
Silvares, E. F. M., \& Gongora, M. A. N. (1998). Psicologia clínica comportamental: a inserção da entrevista com adultos e crianças. São Paulo: Edicon.

Souza, Cecília de Mello e, Leila Adesse . Magnitude da violência sexual no Brasil.Cap.3. p34-35. In:Violência sexual no Brasil: perspectivas e desafios, 2005 / organizadoras Cecília de Mello e Souza, Leila Adesse. Brasília: Secretaria Especial de Políticas para as Mulheres, 2005. 188p.

Vizir, P. Bringiotti, M. I., Perone, G., Nyman, A., Tablado, A. Label, H. P., \& Crescini, S. (2004) Absuso sexual infantil. Sistemas familiares y otros sistemas humanos, 20(1-2), $119-132$.

Wagner, A.; Falcke, D.A comunicação em famílias com filhos adolescentes. Disponível em: http://www.scielo.br/pdf/pe/v7n1/v7n1a08.pdf. Acesso em 05. Maio. 2010. 